\title{
Genomic Epidemiology of Salmonella Infantis in Ecuador: From Poultry Farms to Human Infections
}

\section{OPEN ACCESS}

Edited by:

Gabriel Gutkind,

University of Buenos Aires, Argentina

Reviewed by:

Pablo Chacana,

International Trademark Association,

United States

Nora Lía Padola,

National University of Central Buenos

Aires, Argentina

*Correspondence: Fernando González-Candelas

Fernando.Gonzalez@uv.es

Christian Vinueza-Burgos

cvinueza@uce.edu.ec

Specialty section

This article was submitted to

Veterinary Epidemiology and

Economics,

a section of the journal

Frontiers in Veterinary Science

Received: 01 April 2020

Accepted: 20 August 2020

Published: 29 September 2020

Citation:

Mejía L, Medina JL, Bayas R, Salazar CS, Villavicencio F, Zapata S,

Matheu J, Wagenaar JA,

González-Candelas F and Vinueza-Burgos C (2020) Genomic Epidemiology of Salmonella Infantis in

Ecuador: From Poultry Farms to Human Infections.

Front. Vet. Sci. 7:547891 doi: 10.3389/fvets.2020.547891

\author{
Lorena Mejia ${ }^{1,2}$, José Luis Medina ${ }^{3}$, Rosa Bayas ${ }^{1}$, Carolina Satan Salazar ${ }^{4}$, \\ Fernando Villavicencio ${ }^{4}$, Sonia Zapata ${ }^{1}$, Jorge Matheu ${ }^{5}$, Jaap A. Wagenaar ${ }^{6,7}$, \\ Fernando González-Candelas ${ }^{2,8,9 *}$ and Christian Vinueza-Burgos ${ }^{3 *}$
}

${ }^{1}$ Instituto de Microbiología, Colegio de Ciencias Biológicas y Ambientales, Universidad San Francisco de Quito, Quito, Ecuador, ${ }^{2}$ Institute for Integrative Systems Biology, University of Valencia, Valencia, Spain, ${ }^{3}$ Unidad de Investigación de Enfermedades Transmitidas por Alimentos y Resistencia a los Antimicrobianos (UNIETAR), Facultad de Medicina Veterinaria, Universidad Central del Ecuador, Quito, Ecuador, ${ }^{4}$ Centro de Referencia Nacional de Resistencia a los Antimicrobianos, Instituto Nacional de Investigación en Salud Pública "Leopoldo Izquieta Pérez", Quito, Ecuador, ${ }^{5}$ Department of Food Safety and Zoonoses, World Health Organization (WHO), Geneva, Switzerland, ${ }^{6}$ Department of Infectious Diseases and Immunology, Faculty of Veterinary Medicine, Utrecht University, Utrecht, Netherlands, ${ }^{7}$ Wageningen Bioveterinary Research (WBVR), Lelystad, Netherlands, ${ }^{8}$ Joint Research Unit "Infection and Public Health" FISABIO-University of Valencia, Valencia, Spain, ${ }^{9} \mathrm{CIBER}$ (Centro de Investigación Biomédica en Red) in Epidemiology and Public Health, Valencia, Spain

Salmonella enterica is one of the most important foodborne pathogens around the world. In the last years, S. enterica serovar Infantis has become an important emerging pathogen in many countries, often as multidrug resistant clones. To understand the importance of $S$. enterica in the broiler industry in Ecuador, we performed a study based on phenotypic and WGS data of isolates from poultry farms, chicken carcasses and humans. We showed a high prevalence of $S$. enterica in poultry farms $(41.4 \%)$ and chicken carcasses (55.5\%), but a low prevalence (1.98\%) in human samples. S. Infantis was shown to be the most prevalent serovar with a $98.2,97.8$, and $50 \%$ in farms, foods, and humans, respectively, presenting multidrug resistant patterns. All sequenced S. Infantis isolates belonged to ST32. For the first time, a pESI-related megaplasmid was identified in Ecuadorian samples. This plasmid contains genes of antimicrobial resistance, virulence factors, and environmental stress tolerance. Genomic analysis showed a low divergence of $S$. Infantis strains in the three analyzed components. The results from this study provide important information about genetic elements that may help understand the molecular epidemiology of $S$. Infantis in Ecuador.

Keywords: Salmonella Infantis, ST32, broiler, WGS, Ecuador, megaplasmid, multidrug resistance (MDR)

\section{INTRODUCTION}

Foodborne infections caused by Salmonella enterica are of primary importance worldwide. The WHO estimates that Salmonella causes more than 153 million illnesses, 120,281 deaths, and 8.27 million disability-adjusted life years annually (1). As foodstuffs can be contaminated in several parts of the food chain, a "from farm to table" approach is necessary to understand the epidemiology of Salmonella. Although Salmonella can contaminate vegetables, food-producing animals, especially poultry, are considered important sources for human infections $(2,3)$. In Latin American countries, poultry is one of the main sources of protein of animal origin. This is the case of Ecuador, where poultry meat is the most consumed commodity with a yearly per capita consumption of $30.4 \mathrm{Kg}(4)$. 
Previous investigations in Latin America showed that Salmonella enterica serovar Infantis is an increasingly important serotype on poultry farms (5-9). Moreover, this serotype has also been reported to cause infections in local inhabitants and travelers that have visited Latin American countries (10-12). However, no genomic data considering isolates of Salmonella originated from animals, foodstuff, and humans have been released in Latin America so far.

Antimicrobials are commonly used in poultry production as both therapeutics and growth promoters. However, even when antimicrobials are used under technical criteria, they can select resistant strains of Salmonella that pose a public health problem when reaching consumers (13). This is of special concern in developing countries where the misuse of antimicrobials and lack of control is an issue to be addressed.

There is a wide diversity of virulence factors that are essential for pathogenicity of Salmonella in host cells. Among these factors, fimbriae, flagella, plasmids, pathogenicity islands, toxins, and secretion systems are the more frequently associated to pathogenic strains of Salmonella (14).

This research was aimed at describing by phenotyping methods and whole-genome sequencing, the antimicrobial resistance (AMR) characteristics and genetic profiles of Salmonella isolates obtained from broiler farms, broiler carcasses and humans in Quito-Ecuador.

\section{MATERIALS AND METHODS}

\section{Study Design and Sampling}

Samples for Salmonella isolation were collected weekly from November 2017 to November 2018 following the guidelines of the document: "Integrated Surveillance of Antimicrobial Resistance in Foodborne Bacteria" by the World Health Organization (15).

Poultry Farms: 133 flocks from 69 farms were sampled during the study period. For every sampled flock, 25 caeca from 25 chicken were randomly collected at the slaughterhouse level and transported to the laboratory in an ice-box within the next $2 \mathrm{~h}$. Caecal samples are recommended by the WHO because they provide a higher recovery of isolates and better represent contamination of individual animals at the farm level (15). At the laboratory, a sample pool of $25 \mathrm{~g}$ was obtained for bacteriological isolation as previously described (8).

Chicken carcasses: 335 carcasses were collected in three kinds of markets as follows: 125 samples from supermarkets, 126 samples from small shops, and 84 samples from open markets. Sampling of chicken carcasses was performed alternately between the north and south of the city. Each carcass was collected in its original bag and transported to the laboratory in an ice-box within the next $2 \mathrm{~h}$. At the laboratory, $25 \mathrm{~g}$ of breast skin of every carcass were aseptically collected for bacteriological analysis.

Human stool samples: 302 samples were evenly collected in two health care centers located in the urban periphery of Quito (Guamani health care center at the south and Calderon health care center at the north) from patients with two or more episodes of diarrhea or vomiting in the last $24 \mathrm{~h}$. Human stool samples were transported to the laboratory in an ice-box within the next $2 \mathrm{~h}$. Approximately $25 \mathrm{~g}$ of feces were collected for bacteriological analysis.

According to national legislation, ethics approval was not required for poultry farms and chicken carcasses sampling since no animals were sacrificed during this study. For the human component, the project was approved by the bioethics committee from the National Institute of Public Health "Leopoldo Izquieta Pérez" (Protocol ID:CEISH-INSPI-005). The participants were informed about the objective of the study and all volunteers provided a written consent. All personal information was anonymized.

\section{Isolation and Identification of Salmonella enterica}

Salmonella isolation was performed by a method based in the ISO 6579-1:2007 protocol. Briefly, $225 \mathrm{~mL}$ of Buffered Peptone Water (BPW; Difco, BD, Sparks, MD) was added to every sample, homogenized by hand for $1 \mathrm{~min}$ and incubated at $37^{\circ} \mathrm{C}$ for $20 \mathrm{~h}$. Then, $100 \mu \mathrm{L}$ of each enrichment was inoculated onto Modified Semi-solid Rappaport-Vassiliadis agar (MSRV; Oxoid, Basingstoke, UK) in three equidistant points and incubated at $42^{\circ} \mathrm{C}$ for $24 \mathrm{~h}$. Afterwards, plates were examined for the presence of a white halo around of at least one inoculation point. A loopful taken from the edge of the white halo was streaked on a Xylose Lysine Deoxycholate agar (XLD, Difco) and incubated at $37^{\circ} \mathrm{C}$ for $24 \mathrm{~h}$. After incubation, one suspect colony of Salmonella was biochemically confirmed by Triple Sugar Iron (TSI, Difco, BD), Iron Lysine (LIA, BBL, BD), Urea (BBL, BD), and Sulfur Indole Motility tests (SIM, BBL, BD). Isolated colonies were confirmed by PCR as previously described (16). The $95 \%$ confidence interval $\left(\mathrm{CI}_{95 \%}\right)$ for the prevalence of Salmonella at each component was calculated.

\section{Antimicrobial Susceptibility Testing}

All Salmonella isolates were examined by the Kirby-Bauer disk diffusion method with the following antibiotics: sulfamethoxazole + trimethoprim $(25 \mu \mathrm{g})$, gentamicin $(10 \mu \mathrm{g})$, ciprofloxacin $(5 \mu \mathrm{g})$, cefotaxime $(30 \mu \mathrm{g})$, tetracycline $(30 \mu \mathrm{g})$, streptomycin $(10 \mu \mathrm{g})$, chloramphenicol (30 $\mu \mathrm{g})$, cefoxitin $(30 \mu \mathrm{g})$, amikacin $(30 \mu \mathrm{g})$, nitrofurantoin $(300 \mu \mathrm{g})$, azithromycin $(15 \mu \mathrm{g})$, fosfomycin $(200 \mu \mathrm{g})$, ertapenem $(10 \mu \mathrm{g})$, amoxicillin + clavulanic acid $(30 \mu \mathrm{g})$. E. coli ATCC 25922 strain was used as quality control. Results and methods were interpreted according to CLSI 2019 criteria considering all intermediate phenotypes as resistant for further analysis (17).

\section{Detection of Extended Spectrum Beta-Lactamase (ESBL) Genes}

Salmonella isolates that presented resistant phenotypes to beta-lactam antibiotics were further tested by PCR for the identification of ESBL genes. PCR conditions and primers were the ones described by Hasman et al. (18) for bla $a_{C T X-M}$, Olesen et. al (19) for bla $a_{T E M}$, Kruger et al. (20) for bla $a_{C M Y}$ and Arlet et al. (21) for bla ${ }_{S H V}$. Sub-families of bla $a_{C T X-M}$ genes were identified with PCR protocols described by Carattoli et al. (22) for bla $a_{C T X-M-1}$, Jiang et al. (23) for bla $a_{C T X-M-2}$, Hopkins et al. (24) for bla $a_{C T X-M-8}$, Paauw et al. (25) for $b l a_{C T X-M-9}$ and 
Dierikx et al. (26) for $b l a_{C T X-M-14}$. Amplification products were confirmed by gel electrophoresis using a $2 \%$ agarose gel. All PCR products were purified and sequenced at Macrogen Inc (SeulSouth Korea). Obtained sequences were aligned against reference sequences with the online tool ResFinder v3.2 (27).

\section{Whole Genome Sequencing}

For whole genome sequencing (WGS), a selection of Salmonella isolates was made from the animal and food components. When selecting isolates from poultry farms the first positive sample of each farm was considered. For chicken carcasses, the first positive sample of every sampling week in each kind of market was selected. All non-S. Infantis isolates and all isolates from the human component were selected for WGS.

Genomic DNA was extracted using Invitrogen PureLink Genomic DNA Kit (Thermo Fisher Scientific, Walthman, MA, USA) following manufacturer's recommendations for Gramnegative bacterial cell lysates. DNA was quantified using Invitrogen Qubit 3.0 fluorometer (Thermo Fisher Scientific, Walthman, MA, USA), and sequenced with the Illumina NextSeq platform using Nextera XT Library Preparation Kit obtaining $150 \times 2$ bp paired-ends sequences (Illumina, San Diego, CA, USQ). Default parameters were used for all bioinformatic tools and programs unless otherwise specified. Reads were trimmed with Trimmomatic to remove ambiguous nucleotides and those with quality score values $<20$ (28). The programs Fastqc (29) and Multiqc (30) were used for quality assessment.

\section{Serotype Identification}

Salmonella serotypes were identified by PCR as described by Akiba et al. (16). Additionally, serotypes of isolates subjected to WGS were further confirmed by the analysis of their raw sequencing reads using the SeqSero pipeline (31).

\section{MLST Analysis, Antimicrobial Resistance Genes, and Plasmid Detection}

In order to identify MLST sequence types (ST), antimicrobial resistance genes and plasmid sequences, ARIBA (32) was used with PubMLST (33), ResFinder v3.2 (27), and PlasmidFinder 2.1 (34) databases, respectively. Phenotype resistance was compared with the presence of resistance genes found by WGS. Additionally, we performed a mapping against the megaplasmid p-F219 described by Vallejos-Sánchez et al. (35) using BurrowsWheeler Aligner with BWA-MEM algorithm (36). BCFtools and vcfutils from SAMtools (37) were used to obtain the fastq files from SAM files, and the fasta sequences were transformed from fastq with Seqtk (38). The sequences were concatenated and a maximum likelihood phylogenetic tree was obtained with IQTREE2 software (39). As we obtained two well-defined clusters for $S$. Infantis, we annotated one representative of each plasmid cluster with Prokka (40) and performed an orthologous genes analysis (coverage of $90 \%$, similarity on protein sequences of $80 \%$ ) with Proteinortho5 (41). A manual comparison of all genes present in the plasmids was carried out. We performed the same analysis for non-Infantis isolates.

\section{Megaplasmid Analysis}

Two megaplasmids (pESI and p-F219) commonly associated to pathogenic and MDR strains of $S$. Infantis were analyzed in order to identify their relatedness. We used D-Genies (42) to obtain a dot plot of genome comparison, a genome alignment with progressiveMauve (43) in order to identify locally collinear blocks, and an ANI calculation (44) for computing average nucleotide identity in sequences shared by both plasmids.

\section{Core Genome and Metadata Analysis}

A Peruvian S. Infantis strain, FARPER-219 (35), and two Ecuadorian isolates (SRR4019589 and SRR4019602) analyzed by the US Centers for Disease Control and Prevention from two patients that developed salmonellosis after traveling to Ecuador (10) were added as references in the phylogenetic analysis of all $S$. Infantis isolates. From trimmed reads, Spades (45) was used to generate assemblies. Later, genome annotation was performed with Prokka (40). An orthologous genes analysis with the same conditions as for plasmid detection was performed with Proteinortho5 (41). The strict core genes, those present in all the isolates, were extracted with the Proteinortho tool: grab_proteins.pl. Mafft (46) and an in-house script were used for multiple alignment of every gene and subsequent concatenation in a single multiple alignment, respectively. The phylogenetic tree from the core genome alignment was obtained using IQTREE2 (39) with 1,000 bootstrap replicates. The metadata for sample origin, phenotypic antibiotic resistance patterns, and plasmid in silico detection was added to the final tree with iTol tools (47).

\section{RESULTS}

\section{Salmonella Prevalence and Serotype Identification}

Salmonella was present in 41.4\% (55/133; CI $\left._{95 \%}: 33-49.7\right), 55.5 \%$ (186/335; $\left.\mathrm{CI}_{95 \%}: 50.2-60.8\right)$, and $1.98 \%$ (6/302; $\left.\mathrm{CI}_{95 \%}: 0.4-3.6\right)$ in poultry farms, chicken carcasses and human stool samples, respectively. $S$. Infantis accounted for $98.2 \%(n=54)$ of isolates from poultry farms, $97.8 \%(n=182)$ of isolates from chicken carcasses, and one half $(n=3)$ of human sample isolates. Additionally, one isolate was typed as $S$. Enteritidis in broiler flocks; at the retail level one and three isolates were typed as $S$. Typhimurium and $S$. Enteritidis, respectively, while in the human stool samples two isolates were typed as $S$. Enteritidis and one isolate corresponded to monophasic $S$. Typhimurium 4,[5],12:i:(Supplementary Table 1).

\section{Antimicrobial Resistance}

For S. Infantis isolates, antimicrobial resistance rates to nitrofurantoin, tetracycline, sulfamethoxazole + trimethoprim, streptomycin, gentamicin, cefotaxime, ciprofloxacin and chloramphenicol ranged from 64.8 to $100 \%$. On the other hand, fosfomycin and azithromycin resistance rates were lower, ranging from 0 to $42.6 \%$. Only one isolate from a stool sample presented phenotypic resistance to amikacin while none of the Salmonella isolates in this study was resistant to ertapenem (Table 1). 
TABLE 1 | Number of S. Infantis isolates resistant to each tested antimicrobial.

\begin{tabular}{|c|c|c|c|}
\hline \multirow[t]{2}{*}{ Antimicrobial } & \multicolumn{3}{|c|}{ Number $(\%)$ of resistant isolates } \\
\hline & $\begin{array}{l}\text { Poultry farms } \\
\text { (farm) }\end{array}$ & $\begin{array}{c}\text { Chicken } \\
\text { carcasses (food) }\end{array}$ & $\begin{array}{c}\text { Stool samples } \\
\text { (human) }\end{array}$ \\
\hline Nitrofurantoin & $54(100)$ & $180(99.4)$ & $2(66.7)$ \\
\hline Tetracycline & $54(100)$ & $176(97.2)$ & $3(100)$ \\
\hline $\begin{array}{l}\text { Sulfamethoxazole + } \\
\text { trimethoprim }\end{array}$ & $44(81.5)$ & 158 (87.3) & 1 (33.3) \\
\hline Streptomycin & $46(85.2)$ & $154(85.1)$ & $3(100)$ \\
\hline Gentamicin & 45 (83.3) & $155(85.6)$ & $2(66.7)$ \\
\hline Cefotaxime & $51(94.4)$ & $150(82.9)$ & 1 (33.3) \\
\hline Chloramphenicol & 45 (83.3) & 149 (82.3) & $2(66.7)$ \\
\hline Ciprofloxacin & $35(64.8)$ & $116(64.1)$ & 1 (33.3) \\
\hline Fosfomycin & $23(42.6)$ & $68(37.6)$ & 1 (33.3) \\
\hline Azithromycin & $10(18.5)$ & $31(17.1)$ & $0(0)$ \\
\hline Cefoxitin & $7(13)$ & $11(6.1)$ & $0(0)$ \\
\hline $\begin{array}{l}\text { Amoxicillin + clavulanic } \\
\text { acid }\end{array}$ & $7(13)$ & 7 (3.9) & $0(0)$ \\
\hline Amikacin & $0(0)$ & $0(0)$ & 1 (33.3) \\
\hline Ertapenem & $0(0)$ & $0(0)$ & $0(0)$ \\
\hline
\end{tabular}

TABLE 2 | Antimicrobial resistance patterns of S. Enteritidis, S. Typhimurium, and monophasic S. Typhimurium 4,[5],12:i:-.

\begin{tabular}{lcccc}
\hline $\begin{array}{l}\text { Resistant } \\
\text { pattern }\end{array}$ & $\begin{array}{c}\text { No. } \\
\text { Antimicrobial } \\
\text { clases }\end{array}$ & S. Enteritidis & $\begin{array}{c}\text { S. } \\
\text { Typhimurium }\end{array}$ & $\begin{array}{c}\text { Monophasic } \\
\text { S. } \\
\text { Typhimurium } \\
\text { 4,[5],12:i:- }\end{array}$ \\
\hline SAQBTFN & 7 & & \\
SAQTFNM & 7 & 1 & & \\
SABTFNP & 7 & 1 & & \\
SABTFN & 6 & & & \\
QFM & 3 & 1 & & \\
$\mathrm{~N}$ & 1 & $3^{*}$ & & \\
\end{tabular}

*1 isolate obtained from poultry farms and 2 isolates from human stool samples. Sulfonamide $(S)$, aminoglycosides $(A)$, quinolones $(Q)$, Beta-lactams $(B)$, tetracyclines $(T)$, phenicol $(F)$, nitrofuran $(N)$, macrolides $(M)$, Fosfomycin $(P)$.

Considering antimicrobial classes that were tested, S. Infantis isolates presented 43 antimicrobial resistance patterns. With the exception of one isolate from a stool sample, all isolates showed multidrug-resistant phenotypes. Importantly, 87 and $82 \%$ of isolates from poultry farms and chicken carcasses, respectively, presented resistance from 6 up to 9 classes of antimicrobials (Supplementary Table 2). One S. Infantis isolated from chicken carcasses could not be recuperated for this analysis.

Salmonella serotypes other than $S$. Infantis also presented multiresistant patterns, except for $3 \mathrm{~S}$. Enteritidis isolates that were only resistant to one group of antimicrobials. For this set of isolates, every resistant pattern included isolates belonging to only one serotype (Table 2 ).
One isolate of $S$. Enteritidis, one of $S$. Typhimurium and one of Monophasic S. Typhimurium 4,[5],12:i:-; and 205 isolates of $S$. Infantis were identified as resistant to beta-lactam antibiotics.

Six $S$. Infantis isolates from chicken carcasses and one from poultry farms did not present any of the investigated ESBL genes. All other $S$. Infantis and one $S$. Enteritidis isolated from a carcass presented the $b l_{\mathrm{CTX}-\mathrm{M}-65}$ gene.

\section{Genomic Analysis}

For WGS analysis, 144 isolates (40 from the animal component, 98 from the food component and six from the human component) were selected. Raw sequence data is available under bioproject PRJEB37560. The sequences from three samples were not enough to perform genomic analysis. The obtained average number of reads per strain was 1,356,678 (range $247,022-14,106,025)$ and after the quality control steps, the average number was 1,266,242 (range 228,263-13,094,594) (Supplementary File 1). Average Phred Score was Q34.

MLST typing showed that all $S$. Infantis isolates $(n=137)$ belonged to ST32. The five $S$. Enteritidis isolates belonged to ST11. Additionally, the single isolates of $S$. Typhimurium and monophasic S. Typhimurium 4,[5],12:i:- belonged to ST19 and ST2379, respectively (Supplementary Table 1).

The strict core genome of all $S$. Infantis included in the analysis corresponded to 3,552 genes and spanned $3,161,448$ bp, 1,414 of which were variable (SNPs). The alignment of the concatenated genes present in this core was used to obtain a maximum-likelihood tree using FARPER 219 as outgroup (Figure 1). This strain was chosen because it was isolated in Peru, a neighbor country to Ecuador. Despite its inclusion in ST32, FARPER-219 presented genetic divergence with the Ecuadorian strains. The two Salmonella genomes from the USA (SRR4019589, SRR4019602) grouped indistinctive with some of the genomes of this study. Notably, the analyzed strains did not group according to their sampling origin or their phenotypic resistance patterns.

Genes of antimicrobial resistance were also confirmed with WGS data (Supplementary File 2). For most of the antimicrobial classes (folate pathway inhibition, aminoglycoside, beta-lactams, tetracyclines, fosfomycin, and phenicol) correspondence rates were higher than $80 \%$. However, no genes responsible for the phenotypic resistance to quinolones, nitrofurans, and macrolides were found in sequenced isolates (Table 3 ).

Regarding virulence genes, sifA, sseL, $p i p B$, sopD2, and srlP (part of SPI 2) were found in the core genome of all $S$. Infantis strains. The lpf operon that encodes the long polar fimbrae (LPF), the fim gene cluster that encodes type 1 fimbriae, and the csg operons that encodes the Tafi fimbriae (Thin aggregative fimbriae) were also present in these genomes.

The presence of plasmids was confirmed in silico by PlasmidFinder. Only one S. Infantis isolate (U2449s) presented one plasmid determinant (IncX1 and IncX1_1) despite the multidrug resistance patterns found in our isolates (Figure 1 and Supplementary File 2). To further analyze the low incidence of plasmids, we mapped the raw reads from our samples against the megaplasmid p-F219 described by Vallejos-Sánchez et al. (35). We found two p-F219-like plasmids. The first one, 


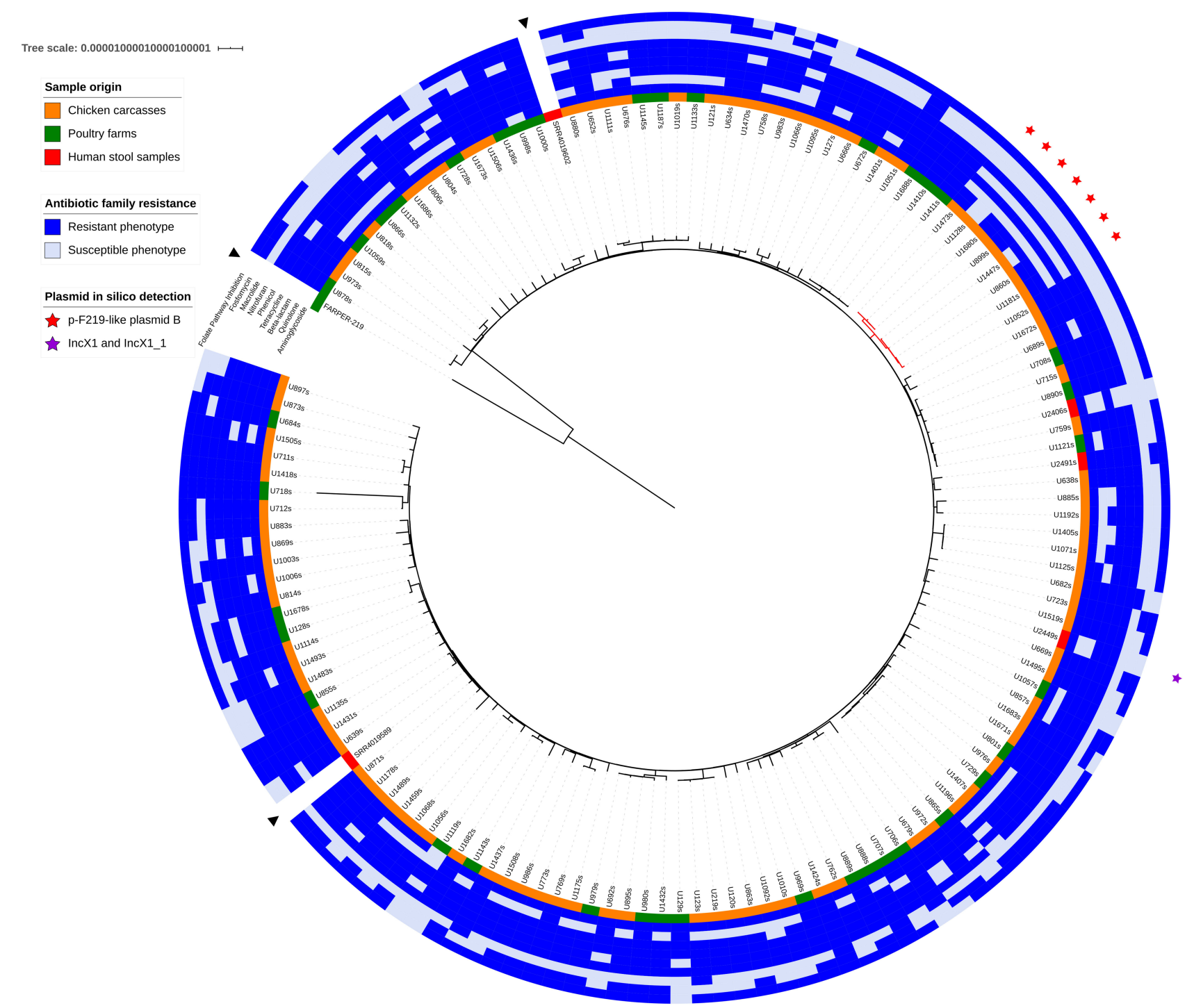

FIGURE 1 | Maximum likelihood phylogenetic tree of core genome alignment of all $137 \mathrm{~S}$. Infantis isolates based on 3,552 genes. Two S. Infantis genomes from Ecuador detected in USA (SRR4019589, SRR4019602) and a Peruvian strain (FARPER-219) were included in the analysis and are indicated with a black triangle. The origin of each sample is colored in red for human stool samples, in green for poultry farms isolates and in orange for chicken carcasses strains. The phenotypic resistance for nine antibiotic families is marked with a blue box. Strains with p-F219-like plasmid B are marked with a red star. The rest of the samples harbor the p-F219-like plasmid A. The purple star indicates the presence of IncX1 and IncX1_1 plasmids in one of the strains. Digital version of the phylogenetic tree is available with iTOL login LMejia at https://itol.embl.de/shared_projects.cgi.

denoted as plasmid $\mathrm{A}$, was present in most of the strains. This plasmid contained 338 genes shared with the p-F219 megaplasmid. The second one, denoted as plasmid B, was present in the remaining seven strains. Plasmid B lacked 72 of the genes present in plasmid $\mathrm{A}$ and presented six exclusive genes (Supplementary File 3). The strains that presented plasmid $\mathrm{B}$ belonged to a monophyletic clade (denoted with a red star in Figure 1). These strains also share susceptibility to fosfomycins, macrolides, phenicols, and beta-lactams. Salmonella strains harboring plasmid B were isolated from chicken carcasses sampled during different weeks of the year, different parts of the city and different types of retail stores (data not shown).
New hypothetical proteins $(n=147)$ were found in both plasmids; 43 exclusively found in plasmid A and five in plasmid B (Supplementary File 3).

The comparison of the p-F219 plasmid with another megaplasmid, commonly found in pathogenic $S$. Infantis strains, pESI plasmid, showed that they share more than $79 \%$ of their sequences ( $>75 \%$ of identity) (Supplementary Figure 1). Besides, we noticed a large genomic inversion in plasmid p-F219 when compared with the pESI plasmid that is also observable in progressiveMauve genome alignment (Supplementary Figure 2). From the ANI calculation, 99.41\% of identity was found in the orthologous genes present in both samples. 
TABLE 3 | Comparison of phenotypic AMR with AMR genes obtained from WGS data.

\begin{tabular}{lccc}
\hline Antibiotic family & Phenotype (\%) & $\begin{array}{c}\text { Phenotype + AMR } \\
\text { gene }^{\mathbf{b}} \text { (\%) }\end{array}$ & $\begin{array}{c}\text { No phenotype + } \\
\text { AMR gene }\end{array}$ \\
\hline $\begin{array}{l}\text { Folate pathway } \\
\text { inhibition }\end{array}$ & 84.56 & 92.17 & 7.83 \\
Aminoglycoside & 97.06 & 100 & 3.03 \\
Quinolone & 58.09 & 1.27 & 0 \\
Beta-lactams & 84.56 & 94.87 & 4.27 \\
Tetracycline & 97.06 & 99.24 & 0.76 \\
Phenicol & 80.88 & 80.91 & 0.36 \\
Nitrofuran & 98.53 & 0 & 0 \\
Macrolide & 17.65 & 0 & 41.18 \\
Fosfomycin & 37.5 & 90.2 & 0 \\
\hline
\end{tabular}

${ }^{a}$ Rate of isolates with phenotypic resistance.

${ }^{b}$ Rate of isolates with phenotypic resistance that presented a resistance gene by WGS analysis.

${ }^{c}$ Rate of isolates without phenotypic resistance that presented a resistance gene by WGS analysis.

In silico plasmid detection in non-Infantis isolates showed the presence of two plasmids in all $S$. Enteritidis strains, while monophasic $S$. Typhimurium 4,[5],12:i:- and $S$. Typhimurium presented 1 and 5 plasmids, respectively (Supplementary Table 1).

\section{DISCUSSION}

In the last decades, there has been a clear rise in the prevalence of multidrug resistant Salmonella enterica worldwide, especially of serovar Infantis $(11,48-50)$.

To better explain the epidemiology of Salmonella in Ecuador, we studied $S$. enterica isolated from poultry farms, chicken carcasses and human stool samples in Quito. The prevalence of Salmonella was high in poultry farms and chicken carcasses, similarly to other studies in the region $(6-8,51)$. Although this research did not look for Salmonella in earlier stages of the broiler production chain, previous studies in Ecuador have reported the importance of compound feed, 1-day-old chicks and broiler pens in the Salmonella exposure of broilers $(7,52)$. These results highlight the necessity to improve broilers production systems in Ecuador toward a better control of Salmonella in the food chain.

In this study, it was also seen that samples from different kinds of markets delivered similar rates of Salmonella isolates, denoting that the geographical distribution of retailers does not influence the presence of Salmonella in carcasses (Supplementary Table 3). On the other hand, all human isolates originated in the southern health care center. However, it must to be considered that the low Salmonella prevalence in human samples could be influenced by the fact that other pathogens might be the main causes of diarrhea. This fact has been studied in Ecuador were other viruses, parasites and bacteria are the main cause of gastroenteritis cases (53-56). Additionally, the state of health carriers should be considered when accessing the real prevalence of Salmonella in humans (57). These circumstances represent limitations of this study and should be considered in future research.

The predominance of $S$. Infantis in this study is in accordance with other reports in the world that show that this serotype is becoming an emergent pathogen. For example, in Europe, $S$. Infantis has been reported to be one of the most common serovars in poultry and in humans (58). The same tendency has been reported in the neighboring country of Peru, where $S$. Infantis is the most prevalent serotype in broilers (6). However, a wider variety of serotypes has been reported in other Latin American countries $(51,59,60)$. This could be explained by the fact that the poultry industry of Peru and Ecuador have close commercial interactions which could determine a common epidemiology of this pathogen. Nevertheless, a recent publication from Chile reported that $24 \%$ of broiler meat samples $(n=$ 361) were positive to the isolation of $S$. Infantis (61). This data highlights the necessity of more research in the field to better understand the epidemiology of Salmonella in the region.

Several studies have shown that control programs of targeted Salmonella serotypes could have favored the occurrence of other serotypes $(2,62)$. This kind of shifts might explain to some extent the low presence of $S$. Enteritidis and Typhimurium among our samples but further research is needed to prove this hypothesis.

Most Salmonella isolates in this study presented multidrug resistance (MDR) phenotypes. This issue is especially evident in $S$. Infantis, as already been seen in Ecuador $(7,8)$ and other countries of the region (63-65). Although in a lower extent, this feature has also been reported in Europe where high rates of MDR (up to $85 \%$ ) are reported in S. Infantis isolated from poultry (66). The high levels of resistance in Salmonella isolates in Latin America could be related to the intensive use of antimicrobials in poultry production as prophylactics, therapeutics, and growth promotors $(67,68)$.

$S$. Infantis isolates belonged to ST32, that is among those more frequently identified within this serovar $(33,69)$. All Ecuadorian $S$. Infantis isolates showed a high genomic similarity with an apparently common origin. However, in order to verify that all in fact share a common ancestor, a larger analysis including isolates from countries around the world is necessary for identifying the origin of this serovar in Ecuador. The close similarity found between isolates from farms, animals and humans show that this pathogen may be responsible for human infections through the food chain.

We did not observe any clear clustering of $S$. Infantis isolates and antibiotic phenotypic resistance patterns, what makes sense since the phylogenetic tree was obtained from the core genome and most of the antimicrobial resistance determinants are expected to be part of the accessory genome.

The resistance genes analysis carried out here could not successfully explain resistance to macrolides, nitrofurans, and quinolones in our isolates. In fact, phenotypic patterns and genetic detection correlation differences have been described previously (70-72), but point mutations not considered in this study may explain these phenotypes. Additional studies are still needed in order to identify the genes or mutations responsible for antimicrobial resistance in $S$. Infantis. 
We found two p-F219-like plasmids (named A and B) present in all the analyzed isolates. Our samples share a significant number of genes with the p-F219 plasmid. The similarity between both p-F219-like plasmids requires a recent common ancestor from which they may have evolved. These plasmids may provide fitness and pathogenic advantages to the strains since they contain several genes for antimicrobial resistance, fimbriae, transposases, and environmental stress tolerance (Supplementary File 3). Other $S$. Infantis isolates around the world have been shown to also harbor pESIrelated megaplasmids, that appear to be the difference between non-pathogenic and pathogenic isolates since it also provides antimicrobial resistance, oxidative stress tolerance, pathogenicity traits, and mercury environmental tolerance $(69,70,73,74)$. Besides, pESI has shown more pathogenicity and increased intestinal inflammation in experimental mice infections when compared to the plasmid-free isolates (73).

Both plasmids (p-F219 and pESI) share regions of very close similarity with an extensive genomic inversion. Genes present in both plasmids share more than $99 \%$ average nucleotide identity suggesting that p-F219 is actually a pESI-like plasmid and the variants found in our samples may also be cataloged as such. A genomic comparison between $S$. Infantis strains showed that large plasmids from multiple isolates actually share a pESI backbone with some genetic plasticity to add different mobile genetic elements due to insertion sequences (75). As pESI-like plasmids confer a MDR phenotype but also several virulence factors and tolerance to environmental stress, their acquisition may have been involved for making $S$. Infantis a successful emerging pathogen worldwide.

The negative results from the unmapped reads from $S$. Enteritidis and $S$. Typhimurium isolates against the p-F219 plasmid suggest that this plasmid may not be widespread among other Salmonella serovars, but more isolates need to be analyzed to confirm this hypothesis.

Other virulence genes in Salmonella are essential for pathogenicity and infection. We looked for some of the more relevant virulence and invasion determinants in the core genome of $S$. Infantis as determined by ProteinOrtho. Some genes that are usually identified as part of the Salmonella pathogenicity island 2 (SPI-2) were found: sifA, sseL, pipB, sopD2, $\operatorname{srlP}(75)$. The long polar fimbrae (LfP), encoded by the lpf operon, was found as putative proteins in all isolates; it is believed that this protein is involved in adhesion and growth on the small intestine mucosa (76), evasion of the host immune system (77). Moreover, variations in these genes may also impact the host range of the bacteria (78). We also found the fim gene cluster that encodes type 1 fimbriae and it is involved in the initiation of biofilm formation (79). Another determinant found in our strains was the csg operon that encodes the Tafi fimbriae (Thin aggregative fimbriae). Tafi is responsible of adhesive activities and biofilm formation (76). The presence of these genes in $S$. Infantis may suggest a pathogenic character of this serotype that, together with the multidrug resistant profiles, represent a potential public health concern.

To the best of our knowledge this is the first report based on Salmonella enterica in Ecuador that uses phenotypic and WGS information to analyze the relatedness of strains isolated from poultry, food and human samples. Isolates from this study show multidrug resistance patterns highlighting the importance of a reduced and better usage of antimicrobials in intensive poultry farms settings. Presence of related megaplasmids together with the core genome high similarity may suggest the dissemination of $S$. Infantis through the food chain to humans. The data presented here has shown the importance of Salmonella enterica serovar Infantis as a foodborne pathogen in Ecuador and provide critical information about its clonality and circulating strains.

\section{DATA AVAILABILITY STATEMENT}

Sequence data are available under bioproject PRJEB37560.

\section{ETHICS STATEMENT}

According to national legislation, ethics approval was not required for poultry farms and chicken carcasses sampling since no animals were sacrificed during this study. For the human component, the project was approved by the bioethics committee from the National Institute of Public Health Leopoldo Izquieta Pérez (Protocol ID was CEISH-INSPI-005). The participants were informed about the study's objective and all volunteers provided a written consent. All personal information was anonymized.

\section{AUTHOR CONTRIBUTIONS}

JM, JW, FV, and CV-B conception and design of the study. JLM, $\mathrm{CS}, \mathrm{FV}$, and RB performed laboratory analysis. JLM and CV-B performed the statistical analysis. JLM, LM, and CV-B organized the databases. $\mathrm{LM}$ and FG-C performed the bioinformatic and genomic analysis. CV-B and LM wrote the first draft of the manuscript. LM, SZ, FG-C, and CV-B contributed to the manuscript revision. All authors contributed to the article and approved the submitted version.

\section{FUNDING}

This project was funded by the WHO Advisory Group on Integrated Survillance on AMR (AGISAR) grant AGISAR$\mathrm{JM} / \mathrm{lg}$ and also funded by projects BFU2017-89594R from MICIN (Spanish Government) and PROMETEO2016-0122 (Generalitat Valenciana, Spain). WGS was co-financed by the European Union through the Operational Program of European Regional Development Fund (ERDF) of Valencia Region (Spain) 2014-2020. LM was recipient of a predoctoral fellowship from Fundación Carolina and Universidad San Francisco de Quito.

\section{ACKNOWLEDGMENTS}

Our acknowledgments to Dr. Gina Watson and Dr. Aida Soto from the OPS/OMS Ecuadorian office for the support in the logistical management of this project. We also thank Mariuxi Japon and Paola Damian for their support with the laboratory work and isolation of Salmonella. Whole genome 
sequences were obtained at Servicio de Secuenciación y Bioinformática (FISABIO, Valencia). Action co-financed by the European Union through the Operational Program of European Regional Development Fund (ERDF) of Valencia Region (Spain) 2014-2020.

\section{REFERENCES}

1. WHO. WHO Estimates of the Global Burden of Foodborne Diseases. Foodborne Disease Burden Epidemiolgy Reference Group 2007-2015. Geneva: World Heal Organization (2015). p. 1-15.

2. Antunes P, Mourão J, Campos J, Peixe L. Salmonellosis: the role of poultry meat. Clin Microbiol Infect. (2016) 22:110-21. doi: 10.1016/j.cmi.2015.12.004

3. Koutsoumanis K, Allende A, Alvarez-Ordóñez A, Bolton D, Bover-Cid S, Chemaly M, et al. Salmonella control in poultry flocks and its public health impact. EFSA J. (2019) 17:e05596. doi: 10.2903/j.efsa.2019.5596

4. CONAVE. Estadísticas Del Sector Avícola. (2020) Available online at: https:// www.conave.org/informacion-sector-avicola-publico/ (accessed February 21, 2020).

5. Donado-Godoy P, Byrne BA, León M, Castellanos R, Vanegas C, Coral A, et al. Prevalence, resistance patterns, and risk factors for antimicrobial resistance in bacteria from retail chicken meat in Colombia. J Food Prot. (2015) 78:751-9. doi: 10.4315/0362-028X.JFP-14-349

6. Valderrama W, Pastor J, Mantilla Salazar J, Ortiz M. Estudio de prevalencia de serotipos de salmonella en granjas avícolas tecnificadas en el perú. Lima. (2014).

7. Vinueza-Burgos C, Baquero M, Medina J, De Zutter L. Occurrence, genotypes and antimicrobial susceptibility of salmonella collected from the broiler production chain within an integrated poultry company. Int J Food Microbiol. (2019) 299:1-7. doi: 10.1016/j.ijfoodmicro.2019.03.014

8. Vinueza-Burgos C, Cevallos M, Ron-Garrido L, Bertrand S, De Zutter L. Prevalence and diversity of salmonella serotypes in ecuadorian broilers at slaughter age. PLoS ONE. (2016) 11:e0159567. doi: 10.1371/journal.pone.0159567

9. Voss-Rech D, Vaz CSL, Alves L, Coldebella A, Leao JA, Rodrigues DP, et al. A temporal study of salmonella enterica serotypes from broiler farms in Brazil. Poult Sci. (2015) 94:433-41. doi: 10.3382/ps/peu081

10. Brown AC, Chen JC, Watkins LKF, Campbell D, Folster JP, Tate H, et al. CTX-M-65 extended-spectrum $\beta$-lactamase-producing salmonella enterica serotype infantis, united states1. Emerg Infect Dis. (2018) 24:2284-91. doi: 10.3201/eid2412.180500

11. Cartelle Gestal M, Zurita J, Paz y Mino A, Ortega-Paredes D, Alcocer I. Characterization of a small outbreak of salmonella enterica serovar infantis that harbour CTX-M-65 in ecuador. Brazilian J Infect Dis. (2016) 20:406-7. doi: 10.1016/j.bjid.2016.03.007

12. Tate H, Folster JP, Hsu C-H, Chen J, Hoffmann M, Li C, et al. Comparative analysis of extended-spectrum- $\beta$-lactamase CTX-M-65-producing salmonella enterica serovar infantis isolates from humans, food animals, and retail chickens in the united states. Antimicrob Agents Chemother. (2017) 61:1-11. doi: 10.1128/AAC.00488-17

13. McDermott PF, Zhao S, Tate $H$. Antimicrobial resistance in nontyphoidal salmonella. Microbiol Spectr. (2018) 6:780-90. doi: 10.1128/9781555819804.ch12

14. Ibarra JA, Steele-Mortimer O. Salmonella - the ultimate insider. Salmonella virulence factors that modulate intracellular survival. Cell Microbiol. (2009) 11:1579-86. doi: 10.1111/j.1462-5822.2009.01368.x

15. WHO. Integrated Surveillance of Antimicrobial Resistance in Foodborne Bacteria. (2017). Available online at: http://apps.who.int/iris/bitstream/10665/ 91778/1/9789241506311_eng.pdf (accessed July 25, 2020).

16. Akiba M, Kusumoto M, Iwata T. Rapid identification of salmonella enterica serovars, typhimurium, choleraesuis, infantis, hadar, enteritidis, dublin and gallinarum, by multiplex PCR. J Microbiol Methods. (2011) 85:9-15. doi: 10.1016/j.mimet.2011.02.002

17. CLSI (Clinical Laboratory Standards Institute). Performance standards for antimicrobial susceptibility testing; twenty-nine informational supplement.

\section{SUPPLEMENTARY MATERIAL}

The Supplementary Material for this article can be found online at: https://www.frontiersin.org/articles/10.3389/fvets. 2020.547891/full\#supplementary-material

In: Weinstein MP, editor. CLSI Document M100-S29. 29th ed. Wayne: Clinical and Laboratory Standards Institute. (2019). p. 32-41.

18. Hasman H, Mevius D, Veldman K, Olesen I, Aarestrup FM. $\beta$-Lactamases among extended-spectrum beta-lactamase (ESBL)-resistant Salmonella from poultry, poultry products and human patients in The Netherlands. $J$ Antimicrob Chemother. (2005) 56:115-21. doi: 10.1093/jac/dki190

19. Olesen I, Hasman H, Aarestrup FM. Prevalence of beta-lactamases among ampicillin-resistant Escherichia coli and salmonella isolated from food animals in Denmark. Microb Drug Resist. (2004) 10:334-40. doi: $10.1089 / \mathrm{mdr} .2004 .10 .334$

20. Kruger T, Szabo D, Keddy KH, Deeley K, Marsh JW, Hujer AM, et al. Infections with nontyphoidal salmonella species producing TEM63 or a novel TEM enzyme, TEM-131, in South Africa. Antimicrob Agents Chemother. (2004) 48:4263-70. doi: 10.1128/AAC.48.11.4263-427 0.2004

21. Arlet G, Rouveau M, Philippon A. Substitution of alanine for aspartate at position 179 in the SHV-6 extended-spectrum beta-lactamase. FEMS Microbiol Lett. (1997) 152:163-7. doi: 10.1016/S0378-1097(97)00196-1

22. Carattoli A, García-Fernández A, Varesi P, Fortini D, Gerardi S, Penni A, et al. Molecular epidemiology of Escherichia coli producing extended-spectrum beta-lactamases isolated in Rome, Italy. J Clin Microbiol. (2008) 46:103-8. doi: 10.1128/JCM.01542-07

23. Jiang X, Zhang Z, Li M, Zhou D, Ruan F, Lu Y. Detection of extendedspectrum beta-lactamases in clinical isolates of pseudomonas aeruginosa. Antimicrob Agents Chemother. (2006) 50:2990-5. doi: 10.1128/AAC.01511-05

24. Hopkins KL, Batchelor MJ, Liebana E, Deheer-Graham AP, Threlfall EJ. Characterisation of CTX-M and AmpC genes in human isolates of Escherichia coli identified between 1995 and 2003 in England and Wales. Int J Antimicrob Agents. (2006) 28:180-92. doi: 10.1016/j.ijantimicag.2006.03.027

25. Paauw A, Fluit AC, Verhoef J, Leverstein-van Hall MA. Enterobacter cloacae outbreak and emergence of quinolone resistance gene in Dutch hospital. Emerg Infect Dis. (2006) 12:807-12. doi: 10.3201/eid1205.050910

26. Dierikx CM, van Duijkeren E, Schoormans AHW, van Essen-Zandbergen A, Veldman K, Kant A, et al. Occurrence and characteristics of extendedspectrum- $\beta$-lactamase- and AmpC-producing clinical isolates derived from companion animals and horses. J Antimicrob Chemother. (2012) 67:1368-74. doi: $10.1093 / \mathrm{jac} / \mathrm{dks} 049$

27. Zankari E, Hasman H, Cosentino S, Vestergaard M, Rasmussen S, Lund O, et al. Identification of acquired antimicrobial resistance genes. J Antimicrob Chemother. (2012) 67:2640-4. doi: 10.1093/jac/dks261

28. Bolger AM, Lohse $M$, Usadel B. Trimmomatic: a flexible trimmer for illumina sequence data. Bioinformatics. (2014) 30:2114-20. doi: 10.1093/bioinformatics/btu170

29. Wingett SW, Andrews S. FastQ screen: a tool for multi-genome mapping and quality control. F1000Research. (2018) 7:1338. doi: 10.12688/f1000research.15931.2

30. Ewels P, Magnusson M, Lundin S, Käller M. MultiQC: summarize analysis results for multiple tools and samples in a single report. Bioinformatics. (2016) 32:3047-8. doi: 10.1093/bioinformatics/btw354

31. Zhang S, Yin Y, Jones MB, Zhang Z, Deatherage Kaiser BL, Dinsmore $\mathrm{BA}$, et al. Salmonella serotype determination utilizing high-throughput genome sequencing data. J Clin Microbiol. (2015) 53:1685-92. doi: 10.1128/JCM.00323-15

32. Hunt M, Mather AE, Sánchez-Busó L, Page AJ, Parkhill J, Keane JA, et al. ARIBA: rapid antimicrobial resistance genotyping directly from sequencing reads. Microb Genomics. (2017) 3:e000131. doi: 10.1099/mgen.0.000131

33. Jolley KA, Bray JE, Maiden MCJ. Open-access bacterial population genomics: BIGSdb software, the PubMLST.org website and their applications. Wellcome Open Res. (2018) 3:124. doi: 10.12688/wellcomeopenres.14826.1 
34. Carattoli A, Zankari E, Garciá-Fernández A, Larsen MV, Lund $\mathrm{O}$, Villa $\mathrm{L}$, et al. In silico detection and typing of plasmids using plasmidfinder and plasmid multilocus sequence typing. Antimicrob Agents Chemother. (2014) 58:3895-903. doi: 10.1128/AAC.02 412-14

35. Vallejos-Sánchez K, Tataje-Lavanda L, Villanueva-Pérez D, Bendezú J, Montalván Á, Zimic-Peralta $\mathrm{M}$, et al. Whole-genome sequencing of a salmonella enterica subsp. Enterica serovar infantis strain isolated from broiler chicken in Peru. Microbiol Resour Announc. (2019) 8:e00826-19. doi: 10.1128/MRA.00826-19

36. Li H, Durbin R. Fast and accurate long-read alignment with burrows-wheeler transform. Bioinformatics. (2010) 26:589-95. doi: 10.1093/bioinformatics/btp698

37. Li H, Handsaker B, Wysoker A, Fennell $\mathrm{T}$, Ruan J, Homer N, et al. 1000 genome project data processing subgroup. The sequence alignment/map format and SAMtools. Bioinformatics. (2009) 25:2078-9. doi: 10.1093/bioinformatics/btp352

38. Li H. Seqtk: Toolkit for Processing Sequences in FASTA/Q Formats Hinxton. (2012).

39. Minh BQ, Schmidt HA, Chernomor O, Schrempf D, Woodhams MD, von Haeseler A, et al. IQ-TREE 2: new models and efficient methods for phylogenetic inference in the genomic era. Mol Biol Evol. (2020) 37:1530-34. doi: $10.1101 / 849372$

40. Seemann T. Prokka: rapid prokaryotic genome annotation. Bioinformatics. (2014) 30:2068-9. doi: 10.1093/bioinformatics/btu153

41. Lechner M, Findeiss S, Steiner L, Marz M, Stadler PF, Prohaska SJ. Proteinortho: detection of (co-)orthologs in large-scale analysis. BMC Bioinformatics. (2011) 12:124. doi: 10.1186/1471-2105-12-124

42. Cabanettes F, Klopp C. D-GENIES: dot plot large genomes in an interactive, efficient and simple way. PeerJ. (2018) 6:e4958. doi: 10.7717/peerj.4958

43. Darling AE, Mau B, Perna NT. Progressivemauve: multiple genome alignment with gene gain, loss and rearrangement. PLoS ONE. (2010) 5:e11147. doi: 10.1371/journal.pone.0011147

44. Yoon S-H, Ha S-M, Lim J, Kwon S, Chun J. A large-scale evaluation of algorithms to calculate average nucleotide identity. Antonie Van Leeuwenhoek. (2017) 110:1281-6. doi: 10.1007/s10482-017-0844-4

45. Nurk S, Bankevich A, Antipov D, Gurevich A, Korobeynikov A, Lapidus A, et al. Assembling genomes mini-metagenomes from highly chimeric reads. In: M Deng, R Jiang, F Sun, X Zhang, editors. Lecture Notes in Computer Science (including subseries Lecture Notes in Artificial Intelligence Lecture Notes in Bioinformatics). Berlin: Springer (2011). p. 158-170. doi: 10.1007/978-3-642-37195-0_13

46. Katoh K, Misawa K, Kuma K, Miyata T. MAFFT: a novel method for rapid multiple sequence alignment based on fast fourier transform. Nucleic Acids Res. (2002) 30:3059-66. doi: 10.1093/nar/ gkf436

47. Letunic I, Bork P. Interactive tree of life (iTOL) v4: recent updates and new developments. Nucleic Acids Res. (2019) 47:W256-9. doi: 10.1093/nar/gkz239

48. Hendriksen RS, Vieira AR, Karlsmose S, Lo Fo Wong DMA, Jensen AB, Wegener HC, et al. Global monitoring of salmonella serovar distribution from the world health organization global foodborne infections network country data bank: results of quality assured laboratories from 2001 to 2007. Foodborne Pathog Dis. (2011) 8:887-900. doi: 10.1089/fpd.201 0.0787

49. EFSA (European Food Safety Authority), ECDC (European Centre for Disease Prevention and Control). The European union summary report on trends and sources of zoonoses, zoonotic agents and food-borne outbreaks in 2012. EFSA J. (2014) 12:e5077. doi: 10.2903/j.efsa.2014. 3547

50. Gymoese P, Kiil K, Torpdahl M, Østerlund MT, Sørensen G, Olsen JE, Nielsen EM, et al. WGS based study of the population structure of salmonella enterica serovar infantis. BMC Genomics. (2019) 20:870. doi: 10.1186/s12864-019-6260-6

51. Donado-Godoy P, Gardner I, Byrne BA, Leon M, Perez-Gutierrez E, Ovalle MV, et al. Prevalence, risk factors, and antimicrobial resistance profiles of salmonella from commercial broiler farms in two important poultry-producing regions of Colombia. J Food Prot. (2012) 75:874-83. doi: 10.4315/0362-028X.JFP-11-458
52. Villagomez S. Aislamiento y serotipificación de salmonella enteritidis, typhimurium e infantis en carcasas de pollo destinadas para consumo humano en un camal industrializado de la provincia de pichincha Quito: Universidad Central del Ecuador. (2015)

53. Vasco G, Trueba G, Atherton R, Calvopiña M, Cevallos W, Andrade $\mathrm{T}$, et al. Identifying etiological agents causing diarrhea in low income ecuadorian communities. Am J Trop Med Hyg. (2014) 91:563-9. doi: 10.4269/ajtmh.13-0744

54. Naranjo A, Cedeño C, Teran E, Castello A, CASERO Research Team. Prevalence of VP4 and VP7 genotypes of human rotavirus in ecuadorian children with acute diarrhea. J Med Virol. (2008) 80:1106-11. doi: $10.1002 /$ jmv. 21181

55. Guderian RH, Ordóñez G, Bossano R. Acute diarrhea associated with a campylobacter and other pathogenic agents in Quito, Ecuador. Boletín Of Sanit Panam. (1987) 102:333-9.

56. Bhavnani D, Goldstick JE, Cevallos W, Trueba G, Eisenberg JNS. Synergistic effects between rotavirus and coinfecting pathogens on diarrheal disease: evidence from a community-based study in northwestern ecuador. Am J Epidemiol. (2012) 176:387-95. doi: 10.1093/aje/kws220

57. Gunn JS, Marshall JM, Baker S, Dongol S, Charles RC, Ryan ET. Salmonella chronic carriage: epidemiology, diagnosis, and gallbladder persistence. Trends Microbiol. (2014) 22:648-55. doi: 10.1016/j.tim.2014.06.007

58. Food E, Authority S. The European union summary report on trends and sources of zoonoses, zoonotic agents and food-borne outbreaks in 2017. EFSA J. (2018) 16:e05500. doi: 10.2903/j.efsa.2018.5500

59. Boscán-Duque L, Arzálluz-Fisher A, Ugarte C, Sánchez D, Wittum T, Hoet A. Reduced susceptibility to quinolones among salmonella serotypes isolated from poultry at slaughter in venezuela. J Food Prot. (2007) 70:2030-35. doi: 10.4315/0362-028X-70.9.2030

60. Medeiros MAN, de Oliveira DCN, Rodrigues DDP, de Freitas DRC. Prevalence and antimicrobial resistance of salmonella in chicken carcasses at retail in 15 Brazilian cities. Rev Panam Salud Publica. (2011) 30:555-60. doi: 10.1590/S1020-49892011001200010

61. Lapierre L, Cornejo J, Zavala S, Galarce N, Sánchez F, Benavides MB, et al. Phenotypic and genotypic characterization of virulence factors and susceptibility to antibiotics in salmonella infantis strains isolated from chicken meat: first findings in chile. Animals. (2020) 10:1049. doi: 10.3390/ani10061049

62. Foley SL, Nayak R, Hanning IB, Johnson TJ, Han J, Ricke SC. Population dynamics of salmonella enterica serotypes in commercial egg and poultry production. Appl Environ Microbiol. (2011) 77:4273-9. doi: 10.1128/AEM.00598-11

63. Da Cunha-Neto A, Carvalho LA, Carvalho RCT, Dos Prazeres Rodrigues D, Mano SB, De Souza Figueiredo EE, et al. Salmonella isolated from chicken carcasses from a slaughterhouse in the state of mato grosso, Brazil: antibiotic resistance profile, serotyping, and characterization by repetitive sequencebased PCR system. Poult Sci. (2018) 97:1373-81. doi: 10.3382/ps/pex406

64. Quesada A, Reginatto GA, Español AR, Colantonio LD, Burrone MS. Resistencia antimicrobiana de salmonella spp aislada de alimentos de origen animal para consumo humano. Rev Peru Med Exp Salud Publica. (2016) 33:32-44. doi: 10.17843/rpmesp.2016.331.1899

65. Rodriguez R, Fandiño C, Donado P, Guzmán L, Verjan N. Characterization of salmonella from commercial egg-laying hen farms in a central region of Colombia. Avian Dis. (2015) 59:57-63. doi: 10.1637/10873-052714-Reg

66. EFSA. The European union summary report on antimicrobial resistance in zoonotic and indicator bacteria from humans, animals and food in 2017/2018. EFSA J. (2020) 18:e06007. doi: 10.2903/j.efsa.2020.6007

67. Vinueza C. Salmonella and Campylobacter in Broilers at Slaughter Age: A Possible Source for Carcasses Contamination in Ecuador. Merelbeke: Faculty of Veterinary Medicine, Ghent University. (2017).

68. Van Boeckel TP, Brower C, Gilbert M, Grenfell BT, Levin S a, Robinson TP, et al. Global trends in antimicrobial use in food animals. Proc Natl Acad Sci USA. (2015) 112:5649-54. doi: 10.1073/pnas.1503141112

69. Hindermann D, Gopinath G, Chase H, Negrete F, Althaus D, Zurfluh K, et al. Salmonella enterica serovar infantis from food and human infections, Switzerland, 2010-2015: poultry-related multidrug resistant clones and an emerging ESBL producing clonal lineage. Front Microbiol. (2017) 8:1322. doi: $10.3389 /$ fmicb. 2017.01322 
70. Bogomazova AN, Gordeeva VD, Krylova EV, Soltynskaya IV, Davydova EE, Ivanova OE, et al. Mega-plasmid found worldwide confers multiple antimicrobial resistance in salmonella infantis of broiler origin in Russia. Int J Food Microbiol. (2020) 319:108497. doi: 10.1016/j.ijfoodmicro.2019.108497

71. Wajid M, Saleemi MK, Sarwar Y, Ali A. Detection and characterization of multidrug-resistant salmonella enterica serovar infantis as an emerging threat in poultry farms of faisalabad, Pakistan. J Appl Microbiol. (2019) 127:248-61. doi: 10.1111/jam.14282

72. Vuthy Y, Lay KS, Seiha H, Kerleguer A, Aidara-Kane A. Antibiotic susceptibility and molecular characterization of resistance genes among Escherichia coli and among salmonella subsp. in chicken food chains. Asian Pac J Trop Biomed. (2017) 7:670-4. doi: 10.1016/j.apjtb.2017.07.002

73. Aviv G, Tsyba K, Steck N, Salmon-Divon M, Cornelius A, Rahav G, et al. A unique megaplasmid contributes to stress tolerance and pathogenicity of an emergent salmonella enterica serovar infantis strain. Environ Microbiol. (2014) 16:977-94. doi: 10.1111/1462-2920.12351

74. Franco A, Leekitcharoenphon P, Feltrin F, Alba P, Cordaro G, Iurescia $\mathrm{M}$, et al. Emergence of a clonal lineage of multidrug-resistant ESBLproducing salmonella infantis transmitted from broilers and broiler meat to humans in Italy between 2011 and 2014. PLoS ONE. (2015) 10:e0144802. doi: 10.1371/journal.pone.0144802

75. Cohen E, Rahav G, Gal-Mor O. Genome sequence of an emerging salmonella enterica serovar infantis and genomic comparison with other S. infantis strains. Genome Biol Evol. (2020)12:223-8. doi: 10.1093/gbe/evaa048

76. Ledeboer NA, Frye JG, McClelland M, Jones BD. Salmonella enterica serovar typhimurium requires the Lpf, Pef, and Tafi fimbriae for biofilm formation on HEp-2 tissue culture cells and chicken intestinal epithelium. Infect Immun. (2006) 74:3156-69. doi: 10.1128/IAI.01428-05
77. Kingsley RA, Weening EH, Keestra AM, Bäumler AJ. Population heterogeneity of salmonella enterica serotype typhimurium resulting from phase variation of the $\mathrm{lpf}$ operon in vitro and in vivo. J Bacteriol. (2002) 184:2352-9. doi: 10.1128/JB.184.9.2352-235 9.2002

78. Gupta SK, Sharma P, McMillan EA, Jackson CR, Hiott LM, Woodley $\mathrm{T}$, et al. Genomic comparison of diverse salmonella serovars isolated from swine. PLoS ONE. (2019) 14:e0224518. doi: 10.1371/journal.pone.02 24518

79. Boddicker JD, Ledeboer NA, Jagnow J, Jones BD, Clegg S. Differential binding to and biofilm formation on, HEp-2 cells by salmonella enterica serovar typhimurium is dependent upon allelic variation in the fimH gene of the fim gene cluster. Mol Microbiol. (2002) 45:1255-65. doi: 10.1046/j.1365-2958.2002. 03121.x

Conflict of Interest: The authors declare that the research was conducted in the absence of any commercial or financial relationships that could be construed as a potential conflict of interest.

Copyright (c) 2020 Mejía, Medina, Bayas, Salazar, Villavicencio, Zapata, Matheu, Wagenaar, González-Candelas and Vinueza-Burgos. This is an open-access article distributed under the terms of the Creative Commons Attribution License (CC BY). The use, distribution or reproduction in other forums is permitted, provided the original author(s) and the copyright owner(s) are credited and that the original publication in this journal is cited, in accordance with accepted academic practice. No use, distribution or reproduction is permitted which does not comply with these terms. 